\title{
MATRIX METALLOPROTEINASES IN CHORIOCARCINOMA CELL LINES: A POTENTIAL REGULATORY ROLE OF EXTRACELLULAR MATRIX COMPONENTS
}

\author{
Erik Maquoi', Agnès Noël, and Jean-Michel Foidart \\ Laboratory of Biology \\ University of Liège \\ Tower of Pathology (B23 Sart Tilman) \\ B-4000 Liège, Belgium
}

\section{INTRODUCTION}

Human placentation is a dynamic process which requires a series of complex, coordinated interactions between maternal and fetal cells. During the first four months of gestation, groups of differentiated trophoblastic cells, also known as extravillous or intermediate trophoblast cells (Kurman et al., 1984), sprout from the basal tip of anchoring villi, migrate through the decidualized endometrium, and invade the wall of the spiral arteries where they replace the endothelial lining to become the endovascular trophoblasts. This trophoblastic invasiveness is characterized by the breaching of multiple basement membranes (BM) and the degradation of the interstitial extracellular matrix (ECM) of the decidualized endometrium.

Many steps of trophoblast infiltration are similar to events that occur during tumor cell invasion. According to the classical model of Liotta and coworkers (1986), invasion by tumor cells involves three main steps: (1) binding of the cell surface receptors to matrix glycoproteins; (2) activation of proteinases and pericellular degradation of matrix components; (3) migration of the cell within the matrix. However, the analogy between tumor cell invasion and trophoblasts penetration of the decidualized endometrium is limited by the fact that during normal pregnancy, trophoblast infiltration is tightly regulated.

Proteins in the ECM, such as laminin, fibronectins, and collagens, have been shown to have dynamic functions in the regulation of cell adhesion, spreading, differentiation and migration (Hynes, 1992; Damsky et al., 1993). Interactions between cells and ECM proteins are mediated by adhesion receptors expressed at the surface of the cell. Among the different adhesion receptors, integrins, a family of heterodimeric transmembrane glycoproteins, are the most ubiquitous and versatile receptors (Hynes, 1992; Pignatelli and Stamp, 1995). In normal pregnancies, a progressive modification of integrin expression at the surface of trophoblast cells has been shown to occur during the differentiation of non-invasive villous cytotrophoblast cells into invasive extravillous trophoblasts (Damsky et al., 1994; Loke and King, 1995). Such a remodeling of the integrin profile enables cells to interact with different ECM components encountered during decidual infiltration. 
This infiltrative process requires not only the capacity for cells to adhere to ECM components but also the ability to digest these components. Several in vivo and in vitro experiments have suggested that trophoblast invasiveness is mediated by a regulated synthesis of matrix degrading enzymes (Lala and Graham, 1990; Bischof and Martelli, 1992; Graham and Lala, 1992). Among these proteolytic enzymes, members of matrix metalloproteinases (MMPs), which share functional and structural characteristics, have been shown to play key roles during placentation (Yagel et al., 1988; Brenner et al., 1989; Fisher et al., 1989; Feinberg et al., 1989; Moll and Lane, 1990; Bischof et al., 1991; Librach et al., 1991; Autio-Harmainen et al., 1992; Fernandez et al., 1992; Blankenship and King, 1994; Hofmann et al., 1994; Polette et al., 1994; Shimonovitz et al., 1994; Maquoi et al., 1997, in press). The MMPs are zinc- and calcium-dependent endopeptidases which degrade components of the ECM at physiological $\mathrm{pH}$, and are inhibited by specific tissue inhibitors (TIMPs). Most of them are produced as inactive proenzymes which are activated by proteolytic cleavage of an amino-terminal pro-domain. The net proteolytic activity will thus depend on the balance between active proteinases and the TIMPs. MMPs play important roles in normal processes such as tissue morphogenesis and wound healing, but are also associated with several pathological conditions involving tissue destruction, including rheumatoid arthritis, and cancer invasion and metastasis (cf., Ries and Petrides, 1995). To date, eleven members of the MMPs family have been identified and classified into three main groups based on substrate specificity (cf., Birkedal-Hansen et al., 1993; Stetler-Stevenson et al., 1993; Cawston, 1995). There are some clear differences in substrate specificity between family members, although in many cases there is significant overlap. The collagenases mainly digest fibrillar collagens; the gelatinases have a high affinity against gelatin (denaturated fibrillar collagens) and cleave triple-helical type IV collagen (the major constituent of basement membranes); and the stromelysins degrade a wide variety of ECM substrates such as proteoglycans, laminin or fibronectin. Recently, new MMPs were described. A macrophage metalloelastase (Belaaouaj et al., 1995), transmembrane-MMPs (MT-MMPs for membrane type MMPs, Sato et al., 1994; Takino et al., 1995; Will and Hinzmann, 1995) and stromelysin-3, a proteinase initially identified in the stroma of breast carcinoma (cf., Basset et al., 1993), have been identified.

The acquisition of an invasive phenotype by early trophoblast cells has been correlated with the ability of these cells to synthesize a large array of MMPs: interstitial collagenase (Yagel et al., 1988; Moll and Lane, 1990), gelatinases A and B (Bischof et al., 1991; Autio-Harmainen et al., 1992; Fernandez et al., 1992; Blankenship and King, 1994; Polette et al., 1994), stromelysins -1, -2, -3 (Brenner et al., 1989; Maquoi et al., 1997), and MT-MMP-1 (Nawrocki et al., 1996). Among these proteinases, cultured first trimester trophoblasts essentially secrete gelatinases, and their invasive potential appears to be mediated by the activity of these enzymes (Librach et al., 1991; Shimonovitz et al., 1994).

However, little is known about the influence of ECM encountered during trophoblast infiltration on the proteolytic activity of these cells. We have therefore analyzed the influence of purified ECM components upon the production of MMPs by extravillous trophoblast cells. However, due to the difficulty to isolate large amounts of pure first trimester extravillous trophoblast cells, we have used choriocarcinoma cell lines (malignant counterparts of invasive extravillous trophoblast cells) which express certain of the characteristics of normal trophoblast (Aplin et al., 1992). Cells were cultured on plastic or thin coats of laminin, fibronectin, collagen I, and collagen IV in order to evaluate the potential effect of these various substrates upon gelatinases secretion. 


\section{Cell Lines}

Human choriocarcinoma cell lines, BeWo and JAr were obtained from the American Type Culture Collection (Rockville, MD, USA). BeWo cells were routinely passaged in HAM's-F12 medium (TechGen) supplemented with $20 \%$ fetal calf serum (FCS, Gibco). JAr cells were maintained in RPMI 1640 medium (TechGen) containing $10 \%$ FCS.

\section{Coating Of Culture Dishes With ECM Components}

Laminin and fibronectin were purified from mouse Engelbreth-Holm-Swarm (EHS) tumors (Timpl et al., 1979) and from human plasma by gelatin affinity chromatography (Yamada, 1983), respectively. Purified type I collagen was prepared from fetal calf skin (Delvoye et al., 1983) and conserved in $0.1 \mathrm{M}$ acetic acid at $-20^{\circ} \mathrm{C}$. Type IV collagen was extracted from EHS tumors according to the procedure described by Timpl et al. (1979). Fibronectin, laminin and collagen types I (Col I) and IV (Col IV) were diluted at $30 \mu \mathrm{g} / \mathrm{ml}$ in Phosphate-Buffered Saline (PBS) and used to coat 24-well (NUNC Multidishes, Denmark) and 96-well (Becton-Dickinson) plates. Dishes were left to air-dry overnight in a laminar flow hood under UV light.

\section{Culture Conditions}

In order to monitor the influence of ECM components on gelatinases secretion, the two choriocarcinoma cell lines were plated on plastic, laminin, fibronectin, Col I and IV. Coated dishes were washed twice with sterile $\mathrm{H}_{2} \mathrm{O}$ and incubated for 1 hour in serum-free medium. Cell suspensions $\left(2 \times 10^{5}\right.$ cells per well) in serum-containing medium were seeded into ECM-coated 24-well plates and incubated at $37^{\circ} \mathrm{C}$ in a humid atmosphere $\left(5 \% \mathrm{CO}_{2}-95 \%\right.$ air). After 24 hours, medium was removed, cells were washed twice with $1 \mathrm{ml}$ of serum-free medium and cultured in $500 \mu \mathrm{l}$ of serum-free medium for 48 hours. Control wells were processed in the same way except that cells were omitted. Conditioned media were collected, centrifugated to eliminate cellular fragments, and stored at $-80^{\circ} \mathrm{C}$. In order to detect ECM-bound gelatinases, ECM coats were extracted in lysis buffer (Brij35 $2 \mathrm{~g} / \mathrm{l}$ in Tris- $\mathrm{HCl}, \mathrm{pH} \mathrm{7.6)}$ ) and dissolved in 10\% SDS non reducing sample buffer.

\section{Cell Adhesion Assay}

Multiwell culture plates (96-wells, Becton Dickinson) were coated with $50 \mu \mathrm{l}$ of PBS containing Bovine Serum Albumin (BSA, fraction V, Sigma), fibronectin, laminin, Col I or Col IV at a concentration of $30 \mu \mathrm{g} / \mathrm{ml}$ (see above). Coated wells were washed twice in sterile water and saturated for 1 hour with $1 \%$ heat denaturated $\left(3\right.$ minutes at $80^{\circ} \mathrm{C}$ ) BSA. Cell suspensions ( $10^{4}$ cells per well) in serum-free media containing $1 \%$ BSA were seeded into protein-coated plates, and at specific times the unattached cells were removed by washing the wells with $100 \mu \mathrm{l}$ of medium containing $1 \%$ BSA and by swirling at $350 \mathrm{rpm}$ for 5 minutes. Attached cells were then incubated for 2 hours at $37^{\circ} \mathrm{C}$ in $100 \mu \mathrm{l}$ of culture medium supplemented with 10\% WST-1 (Boehringer Mannheim). WST-1 is a tetrazolium salt which is cleaved by metabolically active cells and released as a water-soluble formazan dye product. The extent of adhesion was determined by measuring the absorbance of cell-containing wells at $450 \mathrm{~nm}$ with a reference filter of 595 
nm (Titertek Multiscan, Labsystem, Finland). Cell-free blank values were subtracted from each value. In preliminary studies, the relationship between formazan production and cell number was determined by plating out cells from $5-200 \times 10^{2}$ cells per well in 96well microtiter plates, allowing cells to attach for two hours and then determining formazan production. Optical densities showed a linear relationship to cell numbers over the range of densities used (data not shown).

We also evaluated the spreading capacity of the cells on the different matrices. For this purpose, adherent cells (see above) were observed under a phase contrast inverted microscope (Olympus) and the percentage of spread adherent cells was visually determined (at least 100 cells were counted in each condition). Each assay point was derived from quadruplicate wells and the experiments were repeated twice. Statistical analysis of the results was performed using the Student's $T$ test. Differences are considered as statistically significant for $p$ values lower than 0.05 .

\section{Antibodies}

Monoclonal antibodies specific for $\alpha 2$ (P1E6), $\alpha 3$ (P1B5), $\alpha 4$ (P4G9), $\alpha 5$ (P1D6) integrin subunits were purchased from Dako (Denmark); $\alpha 1$ subunit (TS2/7) from $\Upsilon$ Cell Diagnostics, Inc. (MA, USA); $\alpha 6$ subunit from Cappel (Organon Teknika, Belgium); and $\beta 1$ subunit ( $\mathrm{mAb}$ 13) from Becton Dickinson (California, USA), Controls included omission of primary antibody or its replacement with non-specific IgG of the same isotype. These negative controls provided fluorescence patterns indistinguishable from one another.

\section{Flow Cytometry}

Cell suspensions of the two choriocarcinoma cell lines $\left(10^{6}\right.$ cells $\left./ 50 \mu \mathrm{l}\right)$ were incubated with anti-integrin antibodies diluted in serum-containing media for 30 minutes at $4{ }^{\circ} \mathrm{C}$. Cells were then washed, incubated in fluorescein-conjugated rabbit anti-mouse IgG (Dako, Denmark) for 30 minutes at $4^{\circ} \mathrm{C}$, washed again, and fixed in $1 \%$ paraformaldehyde. Fluorescence signals from $10^{4}$ cells were acquired on a FACStar ${ }^{\text {rLus }}$ flow cytometer (Becton Dickinson) to quantify cell surface staining.

\section{Gelatin Zymography And Reversed Zymography}

Substrate polyacrylamide gel electrophoresis (zymography) was used to identified type IV collagenolytic enzymes secreted in conditioned media as described previously (Remacle et al., 1995). Five hundred $\mu$ l of cell-free conditioned media were lyophilized, reconstituted in $50 \mu \mathrm{l}$ of water and mixed with an equal volume of $10 \%$ SDS non reducing sample buffer. Samples were separated at $4^{\circ} \mathrm{C}$ on $10 \%$ SDS-polyacrylamide gels containing $1 \mathrm{mg} / \mathrm{ml}$ gelatin (Sigma). After removal of SDS from the gel by incubation in $2 \%(\mathrm{w} / \mathrm{v})$ Triton $\mathrm{X}-100(2$ washes at room temperature), the gels were incubated at $37^{\circ} \mathrm{C}$ for 18 hours in $50 \mathrm{mM}$ Tris- $\mathrm{HCl}$ buffer, $\mathrm{pH} 7.6$, containing $10 \mathrm{mM}$ $\mathrm{CaCl}_{2}$ and $0.02 \% \mathrm{NaN}_{3}$. Gels were stained for 30 minutes in $0.1 \%$ Coomassie Brillant Blue G-250 in 40\% methanol, 10\% glacial acetic acid, and destained in the same solution without dye. Enzyme activity was evidenced by clear zones of lysis against a blue background. Conditioned media of fibrosarcoma HT1080 cells treated with $1 \mathrm{mM}$ paraaminophenyl-mercuric acetate (APMA) allowed us to identify most of the different proteolytic activities. HT1080 cells are known to secrete a $92 \mathrm{kDa}$ band corresponding to 
latent pro-gelatinase $\mathrm{B}$, as well as a $66 \mathrm{kDa}$ band corresponding to latent pro-gelatinase $\mathrm{A}$ (Wilhelm et al., 1989). Upon APMA treatment, pro-gelatinases A and B are partially processed into lower molecular weight species of $84 \mathrm{kDa}$ and $59 \mathrm{kDa}$, which correspond respectively to activated gelatinase $\mathrm{B}$ and completely activated gelatinase $\mathrm{A}$.

Reverse zymography was performed according to Remacle et al. (1995) with some modifications. Gelatin substrate gels with incorporated recombinant gelatinase A were prepared and concentrated samples were separated and processed as described for gelatin zymography. Gelatinase inhibitors were detected as dark bands against a clear background, indicating the inhibition of lysis of the substrate by gelatinases included in the gel.

\section{RESULTS}

\section{Choriocarcinoma Cell Adhesion To Extracellular Matrix Components}

In order to study the interactions between invasive trophoblast cells and decidual ECM components, we first performed adhesion assays in the presence of purified matrix components which are known to be produced by first trimester decidual cells (Wewer et al., 1985; Aplin and Jones, 1989; Korhonen et al., 1991). Two human choriocarcinoma cell lines (BeWo and JAr) were seeded in the absence of serum onto plastic wells coated with matrix components including laminin, fibronectin, and Col I and IV. Attachment and spreading were monitored for up to four hours. The results obtained after two and four hours are summarized in Figure 1. Although the two cell lines attached to each of the matrix components, adhesion to fibronectin was the most efficient (Figures $1 \mathrm{~A}$ and $\mathrm{C}$ ). However, BeWo cells differed from JAr cells in their ability to interact with collagens. Indeed, Col I and IV promoted cell attachment more efficiently in BeWo than in JAr cells.

Microscopic examination of cells adhering to the different matrix components revealed that cell shape was clearly modulated by the nature of the substrate (Figure 1B and D). BeWo cells spread very extensively and rapidly on fibronectin and, to a lower extent, on Col I and IV (Figure 1B). More than $95 \%$ of adherent cells spread within two hours on fibronectin. On collagen types I and IV, about $70-80 \%$ of cells have spread. In contrast, on laminin, the percentage of spread cells never exceeded $35 \%$, with most cells remaining refractile even after 24 hours (data not shown). The ability of JAr cells to spread on the different ECM components is clearly distinct from that of BeWo cells. Although JAr cells adhered efficiently on all substrates (Figure $1 \mathrm{C}$ ), spreading was much more extensive on fibronectin $(96 \%)$ than on laminin, Col I, and Col IV (15\%, $7 \%$, and $20 \%$ respectively, Figure $1 \mathrm{D}$ ). It appears therefore that the two choriocarcinoma cell lines tested in this study have different capacities to interact with ECM components: BeWo cells have a high affinity for fibronectin and collagens, while JAr cells present an affinity restricted to fibronectin.

\section{Integrins Expression On Choriocarcinoma Cells}

As most of cell-ECM interactions are mediated by specific integrin receptors, we analyzed the expression of these receptors in our two cell lines. Integrins are heterodimeric transmembrane glycoproteins consisting in an $\alpha$ and a $\beta$ chain. At least 14 different $\alpha$ chains and 8 different $\beta$ subunits have been identified so that more than 20 different heterodimeric complexes can be formed (Sonnenberg, 1993). Each of these 
complexes, however, does not only bind to one substrate, but most of the integrins can bind to several different matrix components.
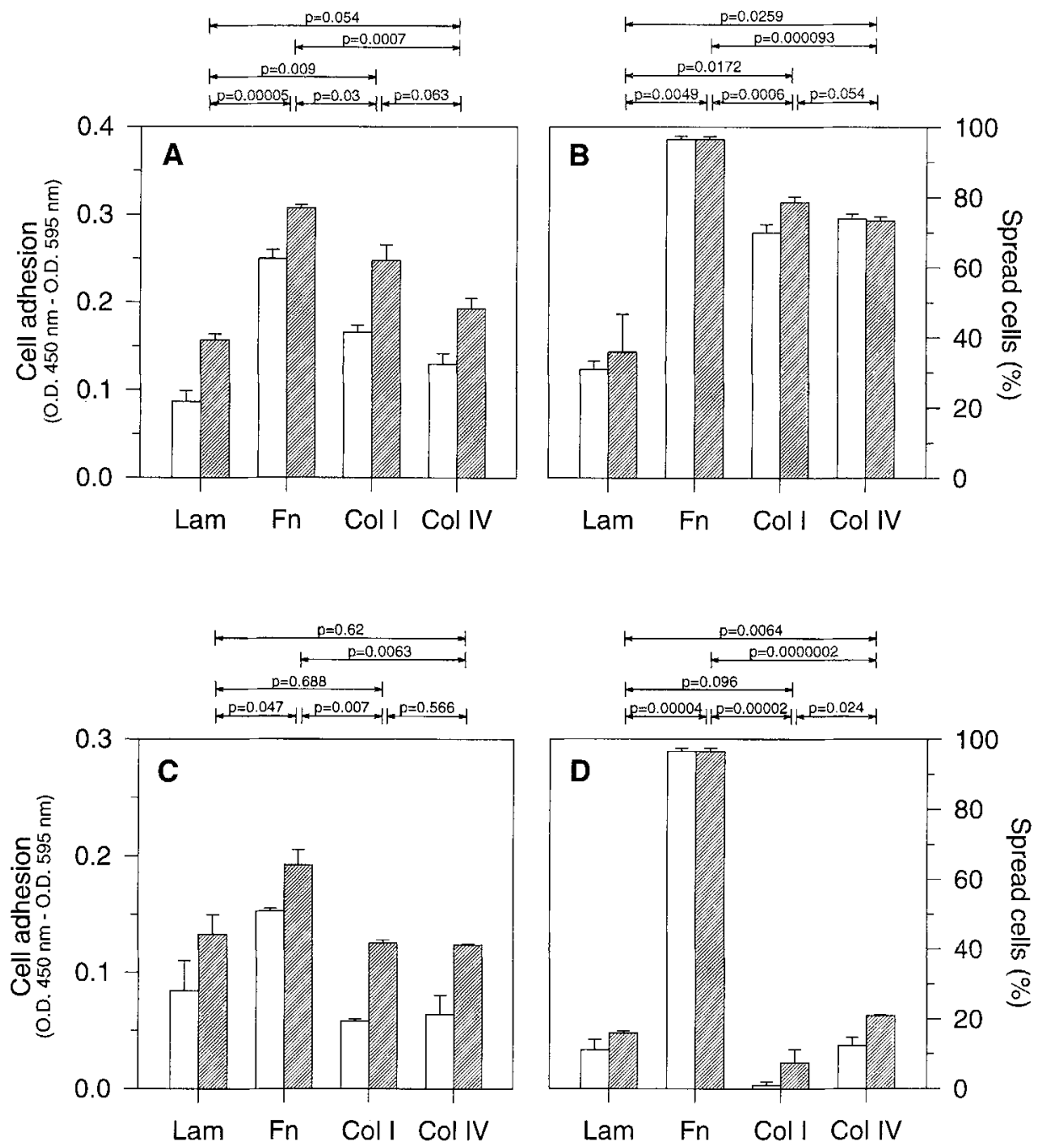

Figure 1. Adhesion and spreading of BeWo (A and B) and JAr (C and D) cells on Laminin (Lam), Fibronectin (Fn), type I collagen (Col I) and type IV collagen (Col IV). The extend of cell adhesion ( $A$ and $C$ ) was determined after 2 (open bars) and 4 (hatched bars) hours. Adhesion was evaluated by measuring the absorbance of the cell-dependent cleavage product of WST-1 at $450 \mathrm{~nm}$ with a reference filter of $595 \mathrm{~nm}$. Spreading (B and D) was evaluated by counting the percentage of adherent cells which spread on the different substrates during the incubation periods used for the adhesion assay. Each assay point was derived from quadruplicate wells and experiments were repeated twice. Results are shown as mean \pm standard errors. Statistical analysis of the results are shown for the 4 hours data. 
By using flow cytometry, we have evaluated the integrin profile of the two choriocarcinoma cell lines. Indirect immunofluorescence staining with monoclonal antibodies, which recognize the $\alpha 1-\alpha 6$, and $\beta 1$ integrin subunits, revealed that both cell lines express $\alpha 3, \alpha 5, \alpha 6$, and $\beta 1$ subunits. However, they differently express the $\alpha 1$ and $\alpha 2$ subunits. BeWo cells express the $\alpha 2$ subunit but not the $\alpha 1$ subunit while JAr cells display at their surface the $\alpha 1$ but not the $\alpha 2$ subunit (Figure 2).
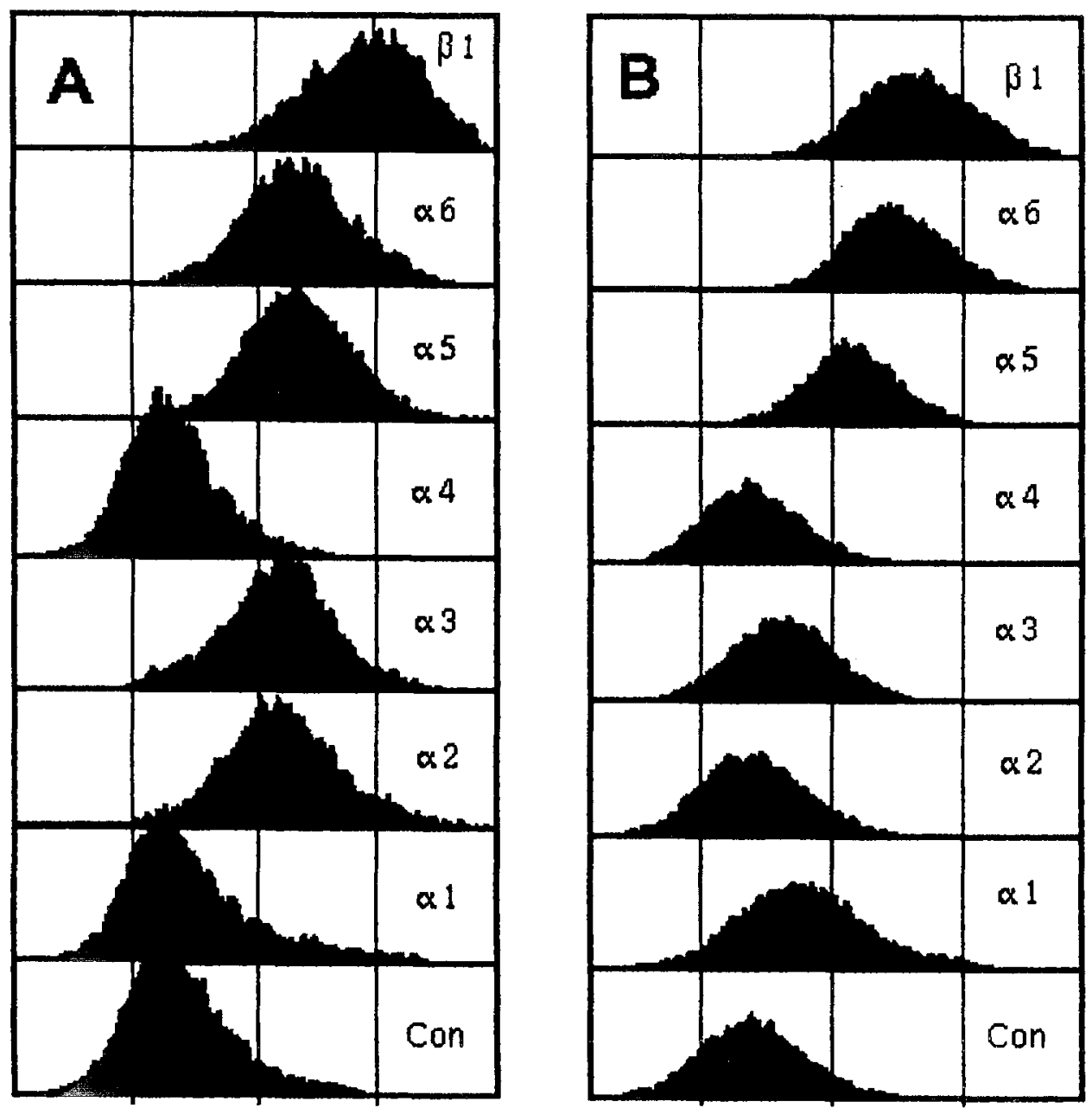

Figure 2. Flow cytometric analysis of integrin expression by BeWo (A) and JAr (B) cells. Horizontal axis represents the log fluorescence intensity, and vertical axis indicates the relative cell counts. Negative controls (Con) include omission of the primary antibody or use of an unrelevant isotype-matched IgG. 

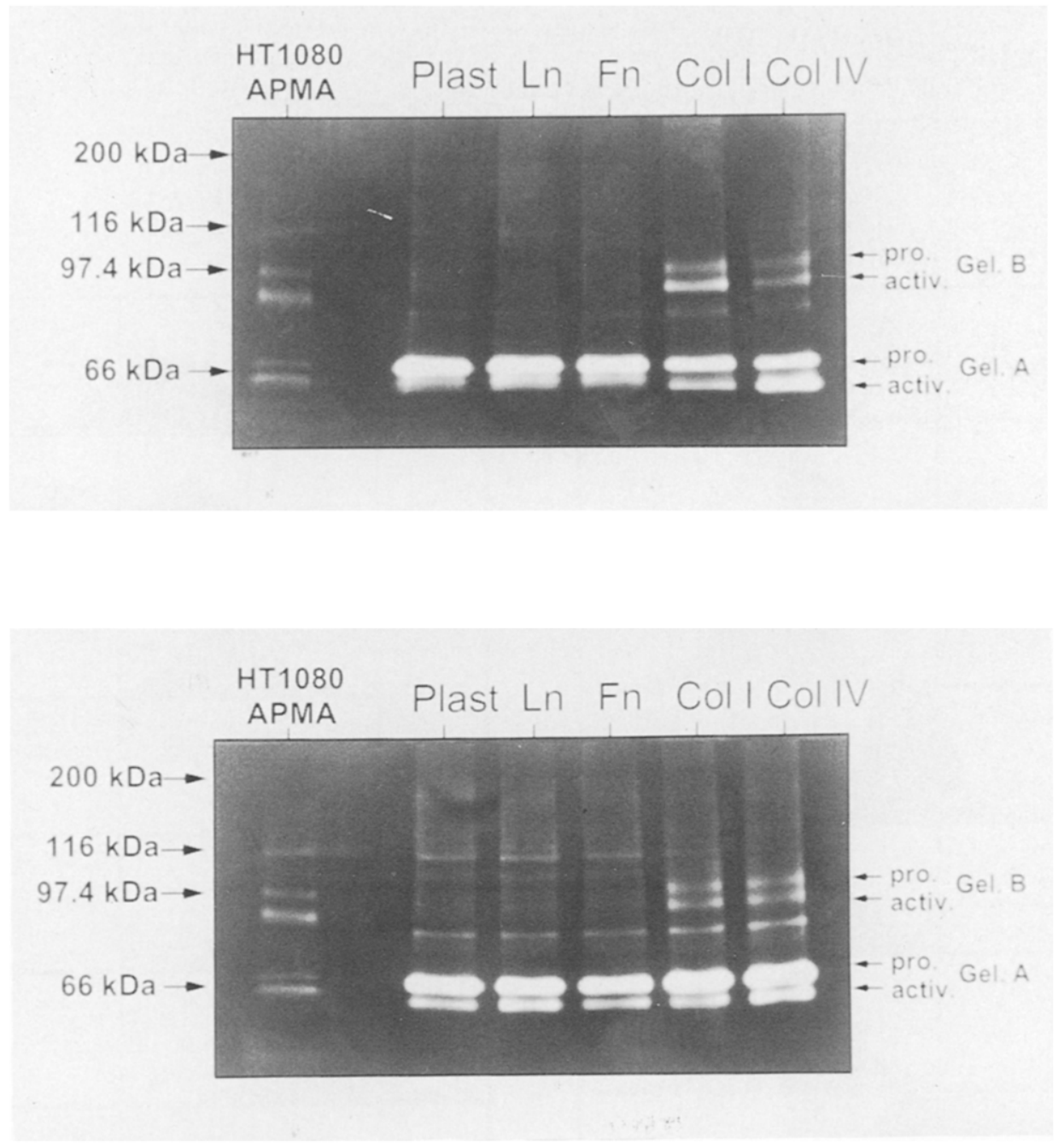

Figure 3. Zymographic analysis of conditioned media from BeWo (A) and JAr (B) cells cultured for two days on plastic (Plast), laminin (Lam), fibronectin (Fn), collagen I (Col I), and collagen IV (Col IV). Gelatinolytic activities were identified by comparing their migration patterns with APMA-activated conditioned media from HT1080 cells (HT1080 APMA). Five major bands were identified in conditioned media of choriocarcinoma cells cultured on collagens: pro-gelatinase B (pro. Gel B; $92 \mathrm{kDa}$ ), active gelatinase B (activ. Gel $\mathrm{B} ; 84 \mathrm{kDa}$ ), pro-gelatinase $\mathrm{A}$ (pro. Gel $\mathrm{A} ; 66 \mathrm{kDa}$ ), intermediate gelatinase $\mathrm{A}(62 \mathrm{kDa})$ and fully activated gelatinase A (activ. Gel A; $59 \mathrm{kDa}$ ). Two unidentified minor bands of 116 and $80 \mathrm{kDa}$ were also detected, especially in conditioned media of JAr cells (B). 


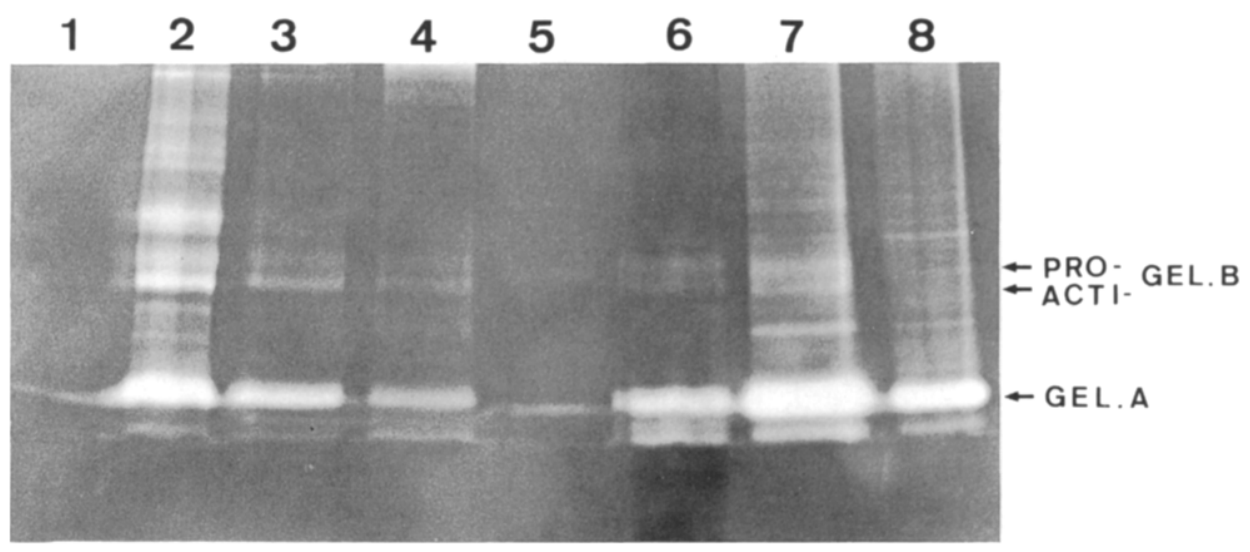

Figure 4. Zymographic analysis of conditioned media and Col IV coats extracts obtained in presence of serum-containing medium or JAr cells. Col IV coats were incubated with JAr cells in serum-containing medium or with serum-supplemented medium alone during 24 hours. Coats were washed twice in serum-free medium and then incubated during 48 hours in $500 \mu 1$ of serum-free medium. Serum-containing medium, conditioned media obtained in presence or absence of JAr cells and the corresponding Col IV coats extracts were collected and analyzed by gelatin zymography. Serumderived pro- and activated gelatinase B (pro- and activ- Gel B, respectively) as well as gelatinase A ( $\mathrm{Gel} \mathrm{A}$ ), initially bound to Col IV coats, are observed in lanes 2, 3, 4,6 and 7. Lane 1: pure Col IV; lane 2: RPMI medium containing 10\% serum (RPMI-10\% serum); lane 3: extract of Col IV coat incubated with RPMI-10\% serum for 24 hours; lane 4: extract of Col IV coat incubated for 24 hours with cell-free RPMI-10\% serum and for 48 hours in serum-free medium; lane 5: conditioned medium from Col IV coat incubated for 24 hours with cell-free RPMI-10\% serum and for 48 hours in serum-free medium; lane 6 : extract of Col IV coat incubated for 24 hours with JAr cells in RPMI-10\% serum and for 48 hours in serum-free medium; lane 7: conditioned medium from Col IV coat incubated for 24 hours with JAr cells in RPMI-10\% serum and for 48 hours in serum-free medium; lane 8: conditioned medium from JAr cells cultivated on plastic for 48 hours in serum-free medium.

\section{Influence Of ECM Components On Metalloproteinases Secretion}

Conditioned media of the two choriocarcinoma cell lines plated on plastic or different purified ECM components were assayed for gelatinolytic activities by gelatin zymography. Several proteinases varying in molecular weight were detected (Figure 3). Addition of $10 \mathrm{mM}$ EDTA in the activation buffer completely inhibited gelatin degradation (data not shown), therefore indicating that all detected proteinases belong to the family of MMPs. On plastic, the conditioned medium of BeWo cells exhibited a strong gelatinolytic band of apparent $66 \mathrm{kDa}$, corresponding to latent pro-gelatinase $\mathrm{A}$, as well as minor bands of $62 \mathrm{kDa}$, corresponding to an intermediate activated form of 
gelatinase $\mathrm{A}$, and an unidentified band of $80 \mathrm{kDa}$ (Figure 3A). In JAr cells conditioned media, a similar gelatinolytic pattern was observed, except that the $62 \mathrm{kDa}$ band was replaced by a completely activated gelatinase $\mathrm{A}$ form of $59 \mathrm{kDa}$ (Figure 3B).

In order to investigate the influence of ECM components on MMPs secretion, the two choriocarcinoma cell lines where plated on fibronectin-, laminin-, Col I-, or Col IVcoated wells (Figure 3). Cultures of these cells on either fibronectin or laminin did not modify the gelatinolytic pattern observed on plastic. When the choriocarcinoma cells were plated on Col I or Col IV, changes in gelatinolytic activities were observed. In BeWo cells, $66 \mathrm{kDa}$ and/or $62 \mathrm{kDa}$ bands were partially converted into the $59 \mathrm{kDa}$ species. However, in conditioned medium of JAr cells, which constitutively processed progelatinase A ( $66 \mathrm{kDa})$ into its fully activated form ( $59 \mathrm{kDa})$, no qualitative modification of pro-gelatinase A activation was detected. Conditioned media of the two cell lines also contained two additional bands of $92 \mathrm{kDa}$ and $84 \mathrm{kDa}$, corresponding respectively to proand activated gelatinase B. However, these two forms of gelatinase B were not secreted by the cells. Indeed, when Col I and IV coats were incubated overnight with cell-free serum-containing media, in order to mimic the plating of cells, we observed that pro- and activated gelatinase B, as well as gelatinase A, were trapped from the serum (Figure 4, lanes 2-4). When cells were added to these matrices, bound gelatinases were released into cells conditioned media. The release of gelatinase B was cell-dependent since no spontaneous release was detected in the absence of cells (Figure 4, lanes 5, 7). Altogether, these results show that, in choriocarcinoma cells, the processing of latent gelatinase $A$ into lower molecular weight active forms was influenced by interactions between cells and specific ECM components such as collagens I and IV.

\section{Secretion Of Metalloproteinase Inhibitors}

Reverse zymography was performed to evaluate the secretion of metalloproteinase inhibitors. One inhibitor band of $21 \mathrm{kDa}$ (corresponding to TIMP-2) was detected in conditioned media of the two cell lines, however, at much higher concentration in JAr cells than in BeWo cells (data not shown). In contrast to gelatinase A activation, TIMP-2 production did not appeared to be influenced by the nature of the ECM.

\section{DISCUSSION}

The processes of implantation and placentation both depend on the penetration and remodeling of the uterine endometrium and vasculature by first trimester trophoblasts. During pregnancy, under the influence of the implanting embryo and the hormonal environment, uterine stromal cells initiate a series of characteristic physiological changes which condition the uterus for infiltration by trophoblasts. Among the numerous changes which take place during the decidualization process, extensive modifications of the composition and organization of endometrial ECMs have been well documented (Wewer et al., 1985, 1986; Kisalus et al., 1987; Aplin et al., 1988; Aplin and Jones, 1989). These modifications include the secretion by decidual cells of a distinct pericellular basement membrane (which contains kaminin, type IV collagen, fibronectin, and heparan sulfate proteoglycans; Wewer et al., 1985; Kisalus et al., 1987; Korhonen et al., 1991; Divers et al., 1995) as well as the remodeling of the decidual interstitial matrix characterized by the disappearance of interstitial collagen VI (which is thought to crosslink fibrils of the major collagens), the reduction in fibril density, and the synthesis of new collagens (Aplin and Jones, 1989; Mylona et al., 1995). Thus, during the first trimester of 
pregnancy, trophoblast infiltration will take place into a sparsely fibrillar network of several matrix proteins (including laminin, fibronectin, and types-I, -III, -IV, -V collagens) which separates the villous cytotrophoblast cells from the maternal vasculature. Concomitant to the endometrial decidualization, another maturation process takes place at the basal tip of anchoring villi. At this precise location, immature proliferative cytotrophoblast anchored to the villous basement membrane progressively differentiate into motile and highly invasive extravillous trophoblasts. During this process, several changes in cell-matrix interactions occur. While cytotrophoblast cells migrate from the villi into the decidua, they modulate their integrin repertoire from being exclusively $\alpha 6 \beta 4$ positive to progressively becoming $\alpha 6 \beta 4$ negative and $\alpha 1 \beta 1, \alpha 3 \beta 1, \alpha 5 \beta 1$, and $\alpha 6 \beta 1$ positive (Aplin, 1993; Damsky et al., 1993, 1994; Korhonen et al., 1991; Burrows et al., 1993). In vitro studies have demonstrated that such an integrin switch was clearly linked to trophoblastic invasiveness. Indeed, interactions between $\alpha 1 \beta 1$ integrin and its ligands (type-IV collagen, laminin) promoted invasion, whereas interactions between $\alpha 5 \beta 1$ and fibronectin reduced trophoblast invasiveness (Damsky et al., 1994).

In this study, we have used two different choriocarcinoma cell lines (BeWo and JAr) as a model system for investigating trophoblast interactions with ECMs components. We first evaluated the capacity of these cells to adhere and spread on purified components of the decidual ECM. Our data demonstrate that BeWo cells adhere most efficiently to both fibronectin and type-I and -IV collagens, whereas adhesion of JAr cells was restricted to fibronectin. Since fibronectin is abundant in decidua in locations where trophoblast infiltration occurs (Wewer et al., 1986; Kisalus et al., 1987; Aplin and Jones, 1989; Damsky et al., 1992, 1993), and may thus provide a transient anchorage for migrating cells, the strong affinity of these choriocarcinoma cells for fibronectin may be considered as a requirement for an extravillous phenotype (Aplin et al., 1992). However, the differential affinity of these two cell lines for collagens suggests that they could present certain phenotypical similarities with two distinct subpopulations of extravillous trophoblast cells. This hypothesis is further illustrated by the analysis of integrin profiles of the two cell lines. Both cell lines express high levels of fibronectin receptor $(\alpha 5 \beta 1$ integrin) but differ by the expression of collagens/laminin receptors. JAr cells express the $\alpha 1 \beta 1$ integrin characteristic of invasive first trimester trophoblast cells (Damsky et al., $1993,1994)$, whereas, in BeWo cells, $\alpha 1 \beta 1$ is replaced by $\alpha 2 \beta 1$, an integrin observed in vivo at the base of trophoblast columns where the differentiation process begins (Loke and King, 1995). Our data are very similar to the integrin patterns previously reported (Hall et al., 1990; Aplin et al., 1992), except that these studies failed to detect the $\alpha 3$ subunit. The combination of our results and data from the literature show that BeWo cells express the $\alpha 2 \beta 1, \alpha 3 \beta 1, \alpha 5 \beta 1$, and $\alpha 6 \beta 4$ integrins, a profile similar to that displayed in vivo by proliferating cytotrophoblast cells during their progression through the trophoblastic columns (Loke and King, 1995). In contrast, JAr cells mainly express the $\alpha 1 \beta 1, \alpha 5 \beta 1$, and $\alpha 6 \beta 1$ integrins, which are characteristic of interstitial trophoblast cells (Loke and King, 1995). Altogether, these results reveal that BeWo and JAr cells are clearly distinct in terms of both adhesive behavior and integrins expression, and might thus mimic two different trophoblastic subpopulations at distinct stages of invasion.

The cell-matrix interactions required for a successful infiltration of the decidua are not restricted to anchorage processes. Since trophoblast cells have to migrate through the decidua, they must degrade ECM components to which they attach. Such a degradation of decidual ECMs requires the action of different proteinases among which members of the MMPs family are known to play key roles. In vivo, invasive first 
trimester trophoblast cells are known to synthesize several MMPs including interstitial collagenase (Yagel et al., 1988; Moll and Lane, 1990), gelatinases A and B (Bischof et al.,1991; Autio-Harmainen et al., 1992; Fernandez et al., 1992; Blankenship and King, 1994; Polette et al., 1994), stromelysins -1, -2, and -3 (Brenner et al., 1989; Maquoi et al., 1997), and MT-MMP-1 (Nawrocki et al., 1996).

In vitro, several groups have reported the synthesis of gelatinases $A$ and $B$ by cultured first trimester cytotrophoblast cells (Fisher et al., 1989; Bischof et al., 1991; Librach et al., 1991; Shimonovitz et al., 1994). In our choriocarcinoma model, we also demonstrated the secretion of high levels of gelatinase $\mathrm{A}$ in both BeWo and JAr cells. In contrast, no gelatinase B was detected in standard culture conditions (e.g., in the absence of ECM components). Similar observations have been previously reported for BeWo cells by Kato and coworkers (1995). The ability of cells to produce gelatinase A has been often correlated with the invasive and migratory capacity of several normal as well as tumoral cell types, thus suggesting that this proteinase is important in the biology of cellular invasion (Stetler-Stevenson, 1990). The production of the proenzyme species appears to be necessary but not sufficient for invasion. Indeed, the aquisition of an invasive phenotype relies on the activation of the secreted latent proenzyme. This activation has been demonstrated to be a two-step proteolytic process leading to the appearance of a partially activated intermediate species, which is subsequently converted into a fully activated enzyme by an autocatalytic cleavage (Strongin et al., 1993; Atkinson et al., 1995).

Recent reports have demonstrated that this activation process is catalyzed by an integral plasma membrane protein, the membrane-type MMP (MT-MMP) to which progelatinase A binds (Sato et al., 1994; Atkinson et al., 1995; Strongin et al., 1995; StetlerStevenson, 1995). Due to its location at the surface of the cell, MT-MMP can bind and activate secreted latent pro-gelatinase $\mathrm{A}$ and, thus localize the degradation of the ECM by concentrating active membrane associated gelatinase $\mathrm{A}$ at sites of cellular invasion (Monsky et al., 1993; Vassalli and Pepper, 1994). We have recently reported the expression of MT-MMP-1 by both first trimester trophoblast cells and decidual cells, suggesting that this new MMP could play a role during placentation (Nawrocki et al., 1996). The analysis of conditioned media of the two choriocarcinoma cell lines revealed that pro-gelatinase A and TIMP-2 secretion were independent of the composition of the $\mathrm{ECM}$ on which they were grown. In contrast, pro-gelatinase A activation was clearly dependent on both cell line and nature of the substrate, thus suggesting the existence of distinct activation processes. BeWo cells secreted large amounts of pro-gelatinase A which was constitutively processed into the intermediate species of $62 \mathrm{kDa}$. However, in the presence of collagen (types I and IV), the fully activated form of $59 \mathrm{kDa}$ was detected, suggesting that collagen can either directly (via collagen-gelatinase A interactions) or indirectly (via the induction of a cellular activation process) induce the processing of the intermediate gelatinase A form. In the later case, the collagen-induced cellular responses have been shown to be largely mediated by the integrin family of collagen receptors such as $\alpha 1 \beta 1, \alpha 2 \beta 1$, and $\alpha 3 \beta 1$ which can transduce information from the ECM to the nucleus of the cell (Thompson et al., 1994). Similar substrate-dependent inductions of progelatinase A processing have already been documented in different cell types including rat testicular cells (Sang et al., 1991), as well as human fibroblasts (Azzam and Thompson, 1992; Seltzer et al., 1994). In contrast, JAr cells constitutively process the progelatinase A into its fully activated form, independently of the nature of the ECM on which they were grown. Whether these differences in the ability of the two cell lines to 
process pro-gelatinase A results from their distinct integrin patterns is currently unknown. However, it is interesting to note that these two cell lines, which potentially mimic two distinct trophoblastic subpopulations, could exhibit distinct mechanisms in order to activate pro-gelatinase $\mathrm{A}$. We are actually investigating the potential involvement of MT-MMP in these activation processes.

In the presence of collagen (I and IV), additional gelatinolytic activities corresponding to both pro- and activated gelatinase B were detected in the conditioned media of both cell lines. These proteinases were shown to be released, in the presence of cells, from serum-derived gelatinases which have been trapped in collagen coats. This observation is of great physiological relevance since decidual cells have been shown, both in vivo and in vitro, to secrete interstitial collagenase, gelatinases and stromelysin (Dieron and Bryant-Greenwood, 1991; Rawdanowicz et al., 1992; Martelli et al., 1993; Polette et al., 1994; Salamonsen, 1994). Once released by decidual cells as inactive proenzymes, these proteinases could be trapped in decidual ECMs. In these locations, they provide a potent, rapidly and targetedly activable store of proteolytic enzymes for infiltrating trophoblast cells, as well as for the uterine ECM remodeling observed during decidualization. Thus, it appears likely that, during the first trimester of pregnancy, the remodeling of the decidua results from the combined activity of both trophoblasts-, as well as decidual-derived proteinases. Moreover, both cell types are also known to secrete TIMPs (the tissue inhibitors of MMPs), which can bind to and inhibit MMPs activities (Lala and Graham, 1990; Polette et al., 1994).

Altogether, these data suggest that the infiltration of the maternal decidua by first trimester extravillous trophoblast cells relies on a precisely regulated balance between MMPs and TIMPs which are secreted by both the invading and invaded compartments.

In conclusion, the combination of our observations and data from the literature suggests that the extensive decidualization of the uterine stroma observed during the first trimester of pregnancy is not a simple protective mechanism to limit trophoblast infiltration (Kirby, 1960, 1965). On the contrary, as suggested by Aplin (1991), it seems likely that decidual tissue is designed for directing trophoblast infiltration rather than acting as a physical barrier to invasion. Indeed, decidualization results in the secretion by stromal cells of unusual ECMs characterized by a reduced collagen fibril density and the presence of several matrix components which can promote trophoblast adhesion, and constitute a reservoir for decidual derived products such as growth factors, proteinases and proteinase inhibitors. In parallel, trophoblast cells modify their expression of ECM receptors which enable them to interact with decidual ECMs components and modulate the trophoblast-derived proteolytic activities in order to penetrate the decidua.

\section{SUMMARY}

BeWo and JAr choriocarcinoma cell lines were used to study cell adhesion and proteolysis, properties thought to be relevant during invasion of maternal decidua by first trimester extravillous trophoblast cells. Both cell lines adhere and spread efficiently on fibronectin, a major component of decidual ECMs. In contrast, they differ by their capacity to interact with laminin and types-I and -IV collagens, which constitute a good substrate for BeWo cells only. These differences are mirrored by the integrin profiles of these cells. BeWo cells express $\alpha 2 \beta 1, \alpha 3 \beta 1, \alpha 5 \beta 1$, and $\alpha 6 \beta 4$ integrins, a profile displayed in vivo by proliferating cytotrophoblast cells during their progression through 
trophoblastic columns, whereas JAr cells mainly express $\alpha 1 \beta 1, \alpha 5 \beta 1$, and $\alpha 6 \beta 1$ integrins which are characteristic of interstitial trophoblast cells. Interactions between trophoblast cells and ECMs are not simply restricted to adhesion processes since they also involve the remodeling of ECMs by tightly regulated proteolytic activities. From this point of view, both cell lines have been shown to actively secrete pro-gelatinase A which is subsequently activated, depending on the nature of the substrate encountered by the cell (different substrate specificities are observed depending on the cell line). These cells are also able to induce the release of proteinases previously trapped by the collagenous component of the ECMs. Altogether, our observations suggest that the infiltration of the maternal decidua by first trimester trophoblast cells rely on extremely complex interactions among which ECMs-derived information appear to play pivotal roles.

\section{ACKNOWLEDGEMENTS}

We gratefully thank Dr. R Greimers for his expert knowledge in flow cytometric analysis. Erik Maquoi is the beneficiary of a grant from the Belgian National Fund for Scientific Research-Télévie Foundation (No. 7.4567.95). This work was supported by grants from the "Communauté Française de Belgique" (Actions de Recherche Concertées 93/98-171), The Commission of European Communities (Concerted European Action BIOMED $1 \mathrm{n}^{\circ}$ PL931346), the "Fonds de la Recherche Scientifique Médicale" (No. 3.9003.92), the "Association contre le Cancer", the "Association Sportive contre le Cancer", the "CGER-Assurances" and "asbl VIVA" 1993/1996, the industry (Boehringer Mannheim $\mathrm{GmbH}$, Penzberg, Germany); the "Centre Anticancéreux près de l'Université de Liège" and the "Fondation Léon Frédéricq" - University of Liège, Belgium.

\section{REFERENCES}

Aplin, J.D., Charlton, A.K. and Ayad, S. (1988) An immunohistochemical study of human endometrial extracellular matrix during the menstrual cycle and first trimester of pregnancy. Cell Tissue Res. 253, 235-240.

Aplin, J.D. and Jones, C.J.P. (1989) Extracellular matrix in endometrium and decidua. In: Placenta As A Model And A Source, (ed.) O. Genbacev and A. Klopper, Plenum Publishing Corporation, pp. 115-128.

Aplin J.D. (1991) Implantation, trophoblast differentiation and haemochorial placentation: Mechanistic evidence in vivo and in vitro. J Cell Science, 99, 681-692.

Aplin, J.D., Sattar, A. and Mould, P. (1992) Variant choriocarcinoma (BeWo) cells that differ in adhesion and migration on fibronectin display conserved patterns of integrin expression. J. Cell Science 103, 435-444.

Aplin J.D. (1993) Expression of integrin $\alpha 6 \beta 4$ in human trophoblast and its loss from extravillous cells. Placenta 14, 203-216.

Atkinson, S.J., Crabbe, T., Cowell, S., Ward, R., Butler, M.J., Sato, H., Seiki, M., Reynolds, J.J. and Murphy, G. (1995) Intermolecular autolytic cleavage can contribute to the activation of progelatinase A by cell membranes. J. Biol. Chem. 270, 30479-30485. 
Autio-Harmainen, H., Hurkainen, T., Niskasaari, K., Höyhtya, M. and Tryggvason, K. (1992) Simultaneous expression of 70 kilodalton type IV collagenase and type IV collagen alpha 1 (IV) chain genes by cells of early human placenta and gestational endometrium. Lab. Invest. 67, 191-200.

Azzam, H.S., and Thompson, E.W. (1992) Collagen-induced activation of the $M r 72,000$ type IV collagenase in normal and malignant human fibroblastoid cells. Cancer Res. $52,4540-4544$.

Basset, P., Wolf, C. and Chambon, P. (1993) Expression of the stromelysin-3 gene in fibroblastic cells of invasive carcinomas of the breast and other human tissues: A review. Br. Cancer Res. Treat. 24, 185-193.

Belaaouaj A., Shipley, J.M., Kobayashi, D.K., Zimonjic, D.B., Popescu, N., Silverman, G.A. and Shapiro, S.D. (1995) Human macrophage metalloelastase. J. Biol. Chem. 270, 14568-14575.

Birkedal-Hansen, H., Moore, W.G.I., Bodden, M.K., Windsor, L.J., Birkedal-Hansen, B., DeCarlo, A. and Engler, J.A. (1993) Matrix metalloproteinases: A review. Crit. Rew. Oral Biol. Med., 4, 197-250.

Bischof, P. and Martelli, M. (1992) Current topic: Proteolysis in the penetration phase of the implantation process. Placenta 13, 17-24.

Bischof, P., Friedli, E., Martelli, M. and Campana, A. (1991) Expression of extracellular matrix-degrading metalloproteinases by cultured human cytotrophoblast cells: Effects of cell adhesion and immunopurification. Am. J. Obstet. Gynecol. 165, 17911801.

Blankenship, T.N. and King, B.F. (1994) Identification of 72-kilodalton type IV collagenase at sites of trophoblastic invasion of macaque spiral arteries. Placenta 15, 177-187.

Brenner, C.A., Adler, R.R., Rappolee, D.A., Pedersen, R.A. and Werb, Z. (1989) Genes for extracellular matrix-degrading metalloproteinases and their inhibitor, TIMP, are expressed during early mammalian development. Genes Dev. 3, 848-859.

Burrows, T.D., King, A. and Loke, Y.W. (1993) Expression of integrins by human trophoblast and differential adhesion to laminin or fibronectin. Hum. Reprod. 8, 475484 .

Cawston, T.E. (1995) Proteinases and inhibitors. Brit. Med. Bull. 51, 385-401.

Damsky, C.H., Fitzgerald, M.L. and Fisher, S.J. (1992) Distribution patterns of extracellular matrix components and adhesion receptors are intricately modulated during first trimester cytotrophoblast differentiation along the invasive pathway, in vivo. J. Clin. Invest. 89, 210-222.

Damsky, C.H., Librach, C., Lim, K.H., Fitzgerald, M.L., McMaster, M.T., Janatpour, M., Zhou, Y., Logan, S.K. and Fisher, S.J. (1994) Integrin switching regulates normal trophoblast invasion. Development 120,3657-3666. 
Damsky, C.H., Sutherland, A. and Fisher, S.J. (1993) Extracellular matrix 5: Adhesive interactions in early mammalian embryogenesis, implantation, and placentation. FASEB J. 7, 1320-1329.

Delvoye, P., Nusgens, B. and Lapière, Ch.M. (1983) The capacity of retracting a collagen matrix is lost by dermatosparactic skin fibroblasts. J. Invest. Dermatol. 81, 267-270.

Dieron, D. and Bryant-Greenwood, G.D. (1991) Collagens, collagenolytic enzymes, and inhibitors in the human fetal membranes and decidua. Troph. Res. 5, 205-216.

Divers, M.J., Bulmer, J.N., Miller, D. and Lilford, R.J. (1995) Beta 1 integrins in third trimester human placentae: No differential expression in pathological pregnancy. Placenta 16,245-260.

Feinberg, R.F., Kao, L.-C., Haimowitz, J.E., Queenan, J.T., Wun, T.-C., Strauss III, J.F. and Kliman, H.J. (1989) Plasminogen activator inhibitor type 1 and 2 in human trophoblasts. Lab. Invest. 61, 20-26.

Fernandez, P.L., Merino, M.J., Nogales, F.F., Charonis, A.S., Stetler-Stevenson, W, and Liotta, L.A. (1992) Immunohistochemical profile of basement membrane proteins and 72 kilodalton type IV collagenase in the implantation placental site. Lab. Invest. $66,572-579$.

Fisher, S.J., Cui, T.-Y., Zhang, L., Hartman, L., Grahl, K., Guo-Yang, Z., Tarpey, J. and Damsky, C.H. (1989) Adhesive and degradative properties of human placental cytotrophoblast cells in vitro. J. Cell Biol. 109, 891-902.

Graham, C.H. and Lala, P.K. (1992) Mechanisms of placental invasion of the uterus and their control. Biochem. Cell Biol. 70, 867-874.

Hall, D.E., Reichardt, L.F., Crowley, E., Holley, B., Moezzi, H., Sonnenberg, A. and Damsky, C.H. (1990) The $\alpha 1 / \beta 1$ and $\alpha 6 / \beta 1$ integrin heterodimers mediate cell attachment to distinct sites on laminin. J. Cell Biol. 110, 2175-2184.

Hofmann, G.E, Glatstein, I., Schatz, F., Heller, D. and Deligdish, L. (1994) Immunohistochemical localization of urokinase-type plasminogen activator and plasminogen activator inhibitors 1 and 2 in early human implantation sites. Am.J. Obstet. Gynecol. 170, 671-676.

Hynes, R.O. (1992) Integrins: Versatility, modulation, and signalling in cell adhesion. Cell $69,11-25$.

Kato, N., Nawa, A., Tamakoshi, K., Kikkawa, F., Suganuma, N., Okamoto, T., Goto, S., Tomoda, Y., Hamaguchi, M. and Nakajima, M. (1995) Suppression of gelatinase production with decreased invasiveness of choriocarcinoma cells by human recombinant interferon beta. Am. J. Obstet. Gynecol. 172, 601-606.

Kirby, D.R. (1960) The development of mouse eggs beneath the kidney capsule. Nature $187,707-708$. 
Kirby, D.R. (1965) The invasiveness of the trophoblast. In: The Farly Conceptus Normal And Abnormal, (ed.) W.W. Park, pp. 68-74.

Kisalus, L.L., Herr, J.C. and Little, C.D. (1987) Immunolocalization of extracellular matrix proteins and collagen synthesis in first-trimester human decidua. Anat. Rec. 218, $402-415$.

Korhonen, M., Ylänne, J., Laitinen, L., Cooper, H.M., Quaranta, V., and Virtanen, I. (1991) Distribution of the $\alpha 1-\alpha 6$ integrin subunits in human developing and term placenta. Lab. Invest. 65, 347-355.

Kurman, R.J., Main, C.S. and Chen, H.C. (1984) Intermediate trophoblast: A distinctive form of trophoblast with specific morphological, biochemical and functional features. Placenta 5, 349-370.

Lala, P.K. and Graham, C.H. (1990) Mechanisms of trophoblast invasiveness and their control: The role of proteases and proteases inhibitors. Cancer Metast. Rev. 9, 369379 .

Librach, C.L., Werb, Z., Fitzgerald, M.L., Chiu, K., Corwin, N.M., Esteves, R., Grobelny, D., Galardy, R. and Damsky, C.H. (1991) 92-kD type IV collagenase mediates invasion of human cytotrophoblasts. J. Cell Biol. 113, 437-449.

Liotta, L.A., Rao, C.N. and Wewer, U.M. (1986) Biochemical interactions of tumor cells with the basement membrane. Ann. Rev. Biochem. 55, 1037-1057.

Loke, Y.W. and King, A. (1995) Trophoblast interaction with extracellular matrix. In: Human Implantation: Cell Biology And Immunology, (eds.) Y.W. Loke and A. King, pp 151-179.

Maquoi, E., Polette, M., Nawrocki, B., Bischof, P., Noël, A., Pintiaux, A., Santavicca, M. Schaaps, J.-P., Pijnenberg, R., Birembaut, P. and Foidart, J.-M. (1997) Expression of stromelysin-3 in the human placenta and placental bed. Placenta 18, in press.

Martelli, M., Campana, A. and Bischof, P. (1993) Secretion of matrix metalloproteinases by human endometrial cells in vitro. J. Reprod. Fertil. 98, 67-76.

Moll, U.M. and Lane, B.L. (1990) Proteolytic activity of first trimester human placenta: localization of interstitial collagenase in villous and extravillous trophoblast. Histochemistry 94, 555-590.

Monsky, W.L., Kelly, T., Lin, C.-Y., Yeh, Y., Stetler-Stevenson, W.G., Mueller, S.C. and Chen, W.-T. (1993) Binding and localization of Mr 72,000 matrix metalloproteinase at cell surface invapodia. Cancer Res. 53, 3159-3164.

Mylona, P., Kielty, C.M., Hoyland, J. and Aplin, J.D. (1995) Expression of type VI collagen in human endometrium and decidua. J. Reprod. Fert. 103, 159-167. 
Nawrocki, B., Polette, M., Marchand, V., Maquoi, E., Beorcha, A., Tournier, J.M., Foidart, J.M., and Birembaut, P. (1996) Membrane-type matrix metalloproteinase-1 expression at the site of human placentation. Placenta 17, 565-572.

Pignatelli, M. and Stamp, G. (1995) Integrins in tumour development and spread. Canc. Sur. 24, 113-127.

Polette, M., Nawrocki, B., Pintiaux, A., Massenat, C., Maquoi, E., Volders, L., Schaaps, J.P., Birembaut, P. and Foidart, J.-M. (1994) Expression of gelatinases A and B and their tissue inhibitors by cells of early and term placenta and gestational endometrium. Lab. Invest. 71, 838-846.

Rawdanowicz, T.J., Hampton, A.L., Nagase, H., Woolley, D.E. and Salamonsen, L.A. (1992) Matrix metalloproteinase production by cultured human endometrial stromal cells: identification of interstitial collagenase, gelatinase A, gelatinase $B$ and stromelysin 1 and their differential regulation by interleukin- $1 \alpha$ and tumor necrosis factor $\alpha$. Proc. Aust. Soc. Med. Res. p. 18.

Remacle, A.G., Baramova, E.N., Weidle, U.H., Krell, H.W. and Foidart, J.M. (1995) Purification of progelatinases A and B by continuous-elution electrophoresis. Prot. Expr. Purif. 6, 417-422.

Ries, C. and Petrides, P.E. (1995) Cytokine regulation of matrix metalloproteinase activity and its regulatory dysfunction in disease. Biol. Chem. Hoppe-Seyler 376, 345-355.

Salamonsen, L.A. (1994) Matrix metalloproteinases and endometrial remodelling. Cell Biol. Intern. 18, 1139-1144.

Sang, Q.-X., Thompson, E.W., Grant, D., Stetler-Stevenson, W.G. and Byers, S.W. (1991) Soluble laminin and arginine-glycine-aspartic acid containing peptides differentially regulate type IV collagenase messenger RNA, activation, and localization in testicular cell culture. Biol. Reprod. 45, 387-394.

Sato, H., Takino, T., Okada, Y., Cao, J., Shinagawa, A., Yamamoto, E. and Seiki, M (1994) A matrix metalloproteinase expressed on the surface of invasive tumor cells. Nature $370,61-65$.

Seltzer, J.L., Lee, A.Y., Akers, K.T., Sudbeck, B., Southon, E.A., Wayner, E.A. and Eisen, A.Z. (1994) Activation of $72-\mathrm{kDa}$ type IV collagenase/gelatinase by normal fibroblasts in collagen lattices is mediated by integrin receptors but is not related to lattice contraction. Exp. Cell Res. 213, 365-374.

Shimonovitz, S., Hurwitz, A., Dushnik, M., Anteby, E., Geva-Eldar, T. and Yagel, S. (1994) Developmental regulation of the expression of 72 and $92 \mathrm{kd}$ type IV collagenases in human trophoblasts: a possible mechanism for control of trophoblast invasion. Am. J. Obstet. Gynecol. 171, 832-838.

Sonnenberg, A. (1993) Integrins and their ligands. Curr. Topics Microbiol. Immunol. 184, 7 33. 
Stetler-Stevenson, W.G. (1990) Type IV collagenases in tumor invasion and metastasis. Cancer Metast. Rev. 9, 289-303.

Stetler-Stevenson, W.G. (1995) Progelatinase A activation during tumor cell invasion. Invasion Metast. 14, 259-268.

Stetler-Stevenson, W.G., Aznavoorian, S. and Liotta, L.A. (1993) Tumor cell interactions with the extracellular matrix during invasion and metastasis. Annu. Rev. Cell Biol. 9, 541-573.

Strongin, A.Y., Collier, I., Bannikov, G., Marmer, B.L., Grants, G.A. and Goldberg, G.I. (1995) Mechanism of cell surface activation of 72-kDa type IV collagenase. J. Biol. Chem. 270, 5331-5338.

Strongin, A.Y., Marmer, B.L., Grant, G.A. and Goldberg, G.I. (1993) Plasma membranedependent activation of the $72-\mathrm{kDa}$ type IV collagenase is prevented by complex formation with TIMP-2. J. Biol. Chem. 268, 14033-14039.

Takino, T., Sato, H., Shinagawa, A. and Seiki, M. (1995) Identification of the second. membrane-type matrix metalloproteinase (MT-MMP-2) gene from a human placenta cDNA library. J. Biol. Chem. 270, 23013-23020.

Thompson, E.W., Yu, M., Bueno, J., Jin, L., Maiti, S.N., Palao-Marco, F.L., Pulyaeva, H., Tamborlane, J.W., Tirgari, R., Wapnir, I. and Azzam, H. (1994) Collagen induced MMP-2 activation in human breast cancer. Breast Canc. Res. Treat. 31, 357-370.

Timpl, R., Bruckner, P. and Fietzek, P. (1979) Characterization of pepsin fragments of basement membrane collagen obtained from a mouse tumor. Eur. J. Biochem. 95, 255-263.

Vassalli, J.D. and Pepper, M.S. (1994) Membrane proteases in focus. Nature 370, 14-15.

Wewer, U.M., Damjanov A..Weiss, J., Liotta, L.A. and Damjanov, I. (1986) Mouse endometrial stromal cells produce basement-membrane components. Differentiation $32,49-58$.

Wewer, U.M., Faber, M., Liotta, L.A. and Albrechtsen, R. (1985) Immunochemical and ultrastructural assessment of the nature of the pericellular basement membrane of human decidual cells. Lab. Invest. 53, 624-633.

Wilhem, S.M., Collier, I.E., Marmer, B.L., Eisen, A.Z., Grant, G.A. and Goldberg, G.I. (1989) SV40-transformed human lung fibroblasts secrete a 92-kDa type IV collagenase which is identical to that secreted by normal human macrophages. J. Biol. Chem. 264, 17213-17221.

Will, H. and Hinzmann, B. (1995) cDNA sequence and mRNA tissue distribution of a novel human matrix metalloproteinase with a potential transmembrane segment Eur. J. Biochem. 231, 602-608. 
Yagel, S., Parhar, R.S., Jeffrey, J.J. and Lala, P.K. (1988) Normal non-metastatic trophoblast cells share in vitro invasive properties of malignant cells. J. Cell Physiol. $136,455-464$.

Yamada, K.M. (1983) Isolation of fibronectin from plasma and cells. In: Immunochemistry Of The Extracellular Matrix, (ed.) H. Furthmayr, pp. 111-123. 